\title{
Non-invasive Autonomic Neuromodulation Is Opening New Landscapes for Cardiovascular Diseases
}

\author{
Mingxian Chen ${ }^{1+}$, Songyun Wang ${ }^{2+}$, Xuping Li $^{1}$, Lilei Yu ${ }^{2}$, Hui Yang ${ }^{1}$, Qiming Liu ${ }^{1}$, \\ Jianjun Tang ${ }^{1 *}$ and Shenghua Zhou ${ }^{1 *}$ \\ ${ }^{1}$ Department of Cardiology, The Second Xiangya Hospital of Central South University, Changsha, China, ${ }^{2}$ Department of \\ Cardiology, Renmin Hospital, Wuhan University, Wuhan, China
}

Autonomic imbalance plays a crucial role in the genesis and maintenance of cardiac disorders. Approaches to maintain sympatho-vagal balance in heart diseases have gained great interest in recent years. Emerging therapies However, certain types of emerging therapies including direct electrical stimulation and nerve denervation require invasive implantation of a generator and a bipolar electrode subcutaneously or result in autonomic nervous system (ANS) damage, inevitably increasing the risk of complications. More recently, non-invasive neuromodulation approaches have received great interest in ANS modulation. Non-invasive approaches have opened new fields in the treatment of cardiovascular diseases. Herein, we will review the protective roles of non-invasive neuromodulation techniques in heart diseases, including transcutaneous auricular vagus nerve stimulation, electromagnetic field stimulation, ultrasound stimulation, autonomic modulation in optogenetics, and light-emitting diode and transcutaneous cervical vagus nerve stimulation (gammaCore).

Keywords: heart, cardiovascular disease, autonomic nervous system, neuromadulation, non-invasive

\section{INTRODUCTION}

Cardiovascular diseases are the leading cause of death with high morbidity and mortality (Roth et al., 2017). Autonomic nervous system (ANS) imbalance is associated with disease progression and negative clinical outcomes (Shen and Zipes, 2014; Lai et al., 2019). It usually participates in the genesis and maintenance of various cardiovascular diseases, including heart failure, arrhythmias, acute myocardial infarction, and hypertension. However, cardiac disorders can in turn further aggravate the imbalance of the ANS, resulting in a vicious cycle between autonomic imbalance and cardiovascular diseases (Chen et al., 2019). Therefore, the ANS has been regarded as an important target to break this vicious cycle (Chen et al., 2015a,b). Due to the limited effectiveness of pharmacologic agents on ANS regulation, device-based neuromodulation has led to interest in applications for cardiovascular disorders. Additionally, cardiac neuromodulation has been successfully performed to modulate the cardiac ANS in the treatment of these disorders by extensive research (Sohinki and Stavrakis, 2019; Waldron et al., 2019).

Approaches via electrical devices or nerve denervation are mainly designed to modulate ANS activity and have become an emerging therapeutic strategy for the treatment of cardiovascular diseases (Cook et al., 2014). According to anatomical placement or nerve denervation, 
neurostimulation therapies can be divided into invasive and noninvasive approaches. Invasive or minimally invasive therapeutic approaches include cervical vagal stimulation (Chen et al., 2016), baroreceptor activation therapy (Sheng et al., 2016), spinal cord stimulation (Lopshire and Zipes, 2014), ganglionated plexi ablation (Zipes, 2017), ganglionated plexi stimulation (Wang S. et al., 2015), renal sympathetic nerve denervation (Yu et al., 2017a,b), and left cardiac sympathetic nerve denervation (Cha et al., 2019). However, these approaches sometimes unavoidably increase the potential risk of hardware-related complications and serious adverse events, including permanent neurological damage. Importantly, electrodes surrounding the nerve trunk sometimes produce scar tissue (fibrosis), which can potentially increase the stimulation threshold. These complications may contribute to the translation failure of some types of devicerelated stimulation (Olshansky, 2016; Sahyouni et al., 2017).

Recently, non-invasive neuromodulation approaches have received great interest in ANS modulation for the treatment of cardiovascular diseases. The "non-invasive" techniques in this review refer to interventions that do not use electrodes around the nerve trunk or cause damage to nerve fibers. Importantly, the advantages of non-invasive approaches, such as low cost, portability, and ease of use, have promoted rapid evolution in recent decades (Schluter et al., 2018). Furthermore, noninvasive approaches are an attractive option for clinicians as novel therapies and are highly recommended for the treatment of cardiovascular diseases. Non-invasive neuromodulation has gradually and widely been applied in experimental evidence and clinical trials of heart diseases. In this review, we discuss the protective impact of non-invasive neuromodulation on the treatment of cardiovascular diseases.

\section{CARDIAC AUTONOMIC NERVOUS SYSTEM AND INVASIVE NEUROMODULATION}

The cardiac autonomic nervous system (CANS) consists of an extrinsic autonomic cardiac nervous system (EACNS) and an intrinsic autonomic cardiac nervous system (ICANS). The EACNS comprises fibers that mediate connections between the heart and the nervous system, whereas the ICANS consists of primarily autonomic nerve fibers once they enter the pericardial sac (Figure 1) (Zipes, 2008; Wickramasinghe and Patel, 2013; Chen et al., 2014).

The ECANS is made up of sympathetic and parasympathetic fibers. The sympathetic fibers are mainly derived from cervical ganglia, stellate ganglia, and thoracic ganglia along with the spinal cord; these fibers form the superior, middle, and inferior cardiac nerves and terminate on the surface of the heart (Witt et al., 2017). Renal sympathetic nerves (RSNs), which include efferent and afferent fibers, are adjacent to the wall of the renal artery and crucial for the production of catecholamines contributing to hypertension. Studies have shown an association between the left stellate ganglion (LSG) and RSNs. Afferent RSNs can affect the nerve activity of the LSG by modulating central sympathetic outflow. The nucleus ambiguous of the medulla oblongata delivers parasympathetic fibers predominantly into the vagal nerve (Ripplinger et al., 2016). The terminals of the vagal nerve relay to the fat pad of the heart and form the ganglion plexus (GP), mainly called the ICANS. GPs are divided into atrial and ventricular GPs located on the surface of the heart. GPs are the integration centers that modulate the intricate autonomic interactions between the ECANS and ICANS (Chen et al., 2014; Brack, 2015).

Afferent fibers are divided into vagal and sympathetic afferents (Burger and Verkuil, 2018). Cardiovascular receptors, including chemoreceptors and baroreceptors, transmit signals from cardiac activity or tissue injury to afferent cardiac nerves. Cardiac afferent fibers deliver signals to the nucleus tractus solitaries (NTS) and dorsomedial spinal trigeminal tract (Zoccal et al., 2014). After NTS receiving information, it projects to caudal ventrolateral medulla (CVM) and rostral ventrolateral medulla (RVM) to coordinate the activity of sympathetic nervous system, and then it finally leads to decrease sympathetic tone outflow. At the same time, NTS also projects information to the dorsal motor nucleus (DMN) of the vagus and contributes to vagal nerve activity enhancement (Ricardo and Koh, 1978). Currently, emerging therapies, including vagus nerve stimulation, baroreflex activation therapy, spinal cord stimulation, renal nerve denervation, left stellate ganglion ablation, GP ablation, and GP stimulation, have been widely applied in cardiovascular diseases (Clancy et al., 2014; Zubcevic et al., 2019).

\section{THE POTENTIAL RISKS OF INVASIVE NEUROMODULATION}

Device-related neuromodulation consists of a generator and electrodes. Implantation of the generator and electrodes requires surgery, especially for children; this approach requires a general anesthetic and at least an overnight stay in the hospital. For instance, the electrodes of some device-based stimulation are designed to surround the nerve trunk to deliver electrical information. A fibrotic scar around the interface induced by the inflammatory response can increase impedance. This leads to the inefficient transduction of electrical signals (Eldabe et al., 2016; Lotti et al., 2017).

The application of invasive neuromodulation is also limited by a variety of potential complications. Complications can be divided into device-related and biologic aspects (Doruk Camsari et al., 2018). Device-related complications include lead fracture or migration, intermittent stimulation, over- or under-stimulation, loose connections, hardware malfunction, battery replacement, and communication failure with the generator (Levy, 2013). Biologic complications consist of epidural hemorrhage, infection, voice disturbances, cough, headache, paralysis, cerebrospinal fluid leakage, pain over the implant site, allergic reactions, skin breakdown, surgical costs, and the need for post-operative monitoring (Levy et al., 2011; Shamji et al., 2015; Petraglia et al., 2016).

Non-invasive neuromodulation is a relatively new and promising method with potential advantages as an alternative 


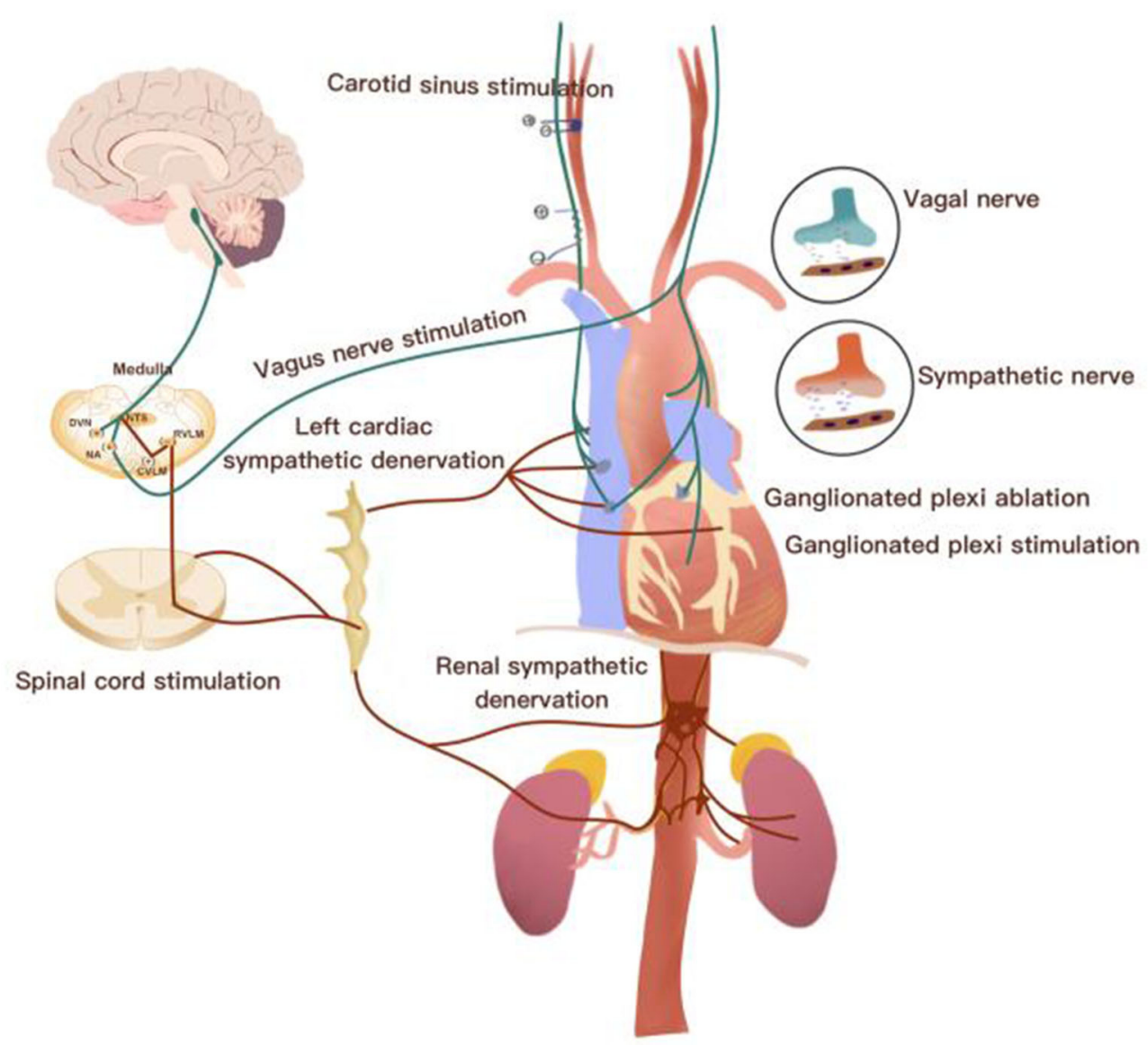

FIGURE 1 | Overview of the neurocardiac axis and invasive neuromodulatory approaches. CVLM, caudal ventrolateral medulla; DVN, dorsal vagal nucleus; IML, intermediolateral cell column; NTS, nucleus of the solitary tract; RVLM, rostroventrolateral medulla.

to invasive neuromodulation. Non-invasive neuromodulation is easier and less invasive than traditional neuromodulation, thus reducing the risk of complications (Eldabe et al., 2016; Cotero et al., 2019).

\section{NON-INVASIVE NEUROMODULATION AND CARDIOVASCULAR DISEASES}

Electrical device stimulation and sympathetic nerve denervation have progressively been a focus of non-pharmaceutical approaches for the treatment of cardiovascular diseases (Lohmeier and Hall, 2019). Recently, current non-invasive neuromodulation techniques have gained particular interest in cardiovascular disorders. They not only provide deep insight into autonomic circuit physiology but also can be applied for therapeutic purposes (Table 1 and Figure 2).

\section{Transcutaneous Auricular Vagus Nerve Stimulation and Cardiovascular Diseases}

The auricular branch of the vagus nerve (ABVN), a powerful nerve entering the brain, is the only afferent peripheral branch of the vagus nerve that is located in the skin. The ABVN delivers information to the central ANS. After integration, it finally causes an increase in vagal nerve activity and a reduction in sympathetic tone. Transcutaneous auricular vagus nerve stimulation (taVNS) is a non-invasive method applied to electrically regulate vagal tone and brain activity by the vagal afferent pathway (Kaniusas et al., 2019a,b). Clancy et al. (2014) demonstrated that ta-VNS could increase parasympathetic predominance assessed by heart rate viability and could reduce sympathetic nerve activity detected by microneurography. Decades ago, ta-VNS was first applied for cognitive, emotional, and neurological modulation, with a similar effect as invasive cervical vagus nerve stimulation. In recent years, because of the novel and noninvasive technology, ta-VNS has been applied in both research and therapy as a medical treatment tool for cardiovascular diseases (Shiozawa et al., 2014; Redgrave et al., 2018).

Recently, as a type of non-invasive neuromodulation, ta-VNS has been gradually and widely applied to treat cardiac diseases, including atrial fibrillation (AF), acute and chronic ischemia diseases, and heart failure induced by autonomic imbalance. Previous studies have shown that high-intensity vagus nerve stimulation induces $\mathrm{HF}$, but low-level vagus nerve stimulation 
TABLE 1 | Studies of non-invasive autonomic neuromodulations in the treatment of cardiovascular diseases.

\begin{tabular}{|c|c|c|c|c|c|c|}
\hline Modulation & References & Species & Parts & Parameters & Models & Results \\
\hline \multirow[t]{11}{*}{$\begin{array}{l}\text { Tragus nerve } \\
\text { stimulation }\end{array}$} & Yu et al. (2013) & Canine & Ear & $\begin{array}{l}\text { The voltage of } 80 \% \text { below the } \\
\text { threshold }\end{array}$ & Atrial fibrillation & $\begin{array}{l}\text { Inhibit AF and electrophysiological } \\
\text { changes }\end{array}$ \\
\hline & Chen et al. (2015c) & Canine & Right Ear & $\begin{array}{l}\text { The voltage of } 80 \% \text { below the } \\
\text { threshold }\end{array}$ & Atrial fibrillation & $\begin{array}{l}\text { Inhibit AF by the expression of } \\
\text { connexs }\end{array}$ \\
\hline & Chen et al. (2015d) & Canine & Left-sided tragus & $\begin{array}{l}\text { The voltage of } 80 \% \text { below the } \\
\text { threshold }\end{array}$ & Atrial fibrillation & Inhibit AF by conexin expression \\
\hline & Wang et al. (2014) & Canine & Left-sided tragus & $\begin{array}{l}\text { The voltage of } 80 \% \text { below the } \\
\text { threshold }\end{array}$ & $\begin{array}{l}\text { Chronic myocardial } \\
\text { infarction }\end{array}$ & $\begin{array}{l}\text { Ameliorate ventricular remodeling and } \\
\text { function }\end{array}$ \\
\hline & $\begin{array}{l}\text { Wang S. et al. } \\
(2015)\end{array}$ & Canine & Left-sided tragus & $\begin{array}{l}\text { The voltage of } 80 \% \text { below the } \\
\text { threshold }\end{array}$ & $\begin{array}{l}\text { Chronic myocardial } \\
\text { infarction }\end{array}$ & $\begin{array}{l}\text { Improve ventricular remodeling by the } \\
\text { expression of collagen, TGF- } \beta \text {, } \\
\text { MMP-9 }\end{array}$ \\
\hline & Yu et al. (2016) & Canines & Left-sided ear & $\begin{array}{l}\text { The voltage of } 80 \% \text { below the } \\
\text { threshold }\end{array}$ & $\begin{array}{l}\text { Chronic myocardial } \\
\text { infarction }\end{array}$ & Inhibit LSG activity and remodeling \\
\hline & Zhou et al. (2016) & Canine & Right tragus & $\begin{array}{l}\text { The voltage of } 80 \% \text { below the } \\
\text { threshold }\end{array}$ & $\begin{array}{l}\text { Ligh-frequency } \\
\text { stimulation of RSG }\end{array}$ & $\begin{array}{l}\text { Suppress RSG activity and } \\
\text { sympathetically induced sinus node } \\
\text { acceleration }\end{array}$ \\
\hline & Zhou et al. (2019) & Rats & Tragus & $\begin{array}{l}(20 \mathrm{~Hz}, 2 \mathrm{~mA}, 0.2 \mathrm{~ms}) \text { was } \\
\text { implemented for } 30 \text { min daily } \\
\text { for } 4 \text { weeks }\end{array}$ & $\begin{array}{l}\text { Heart failure with } \\
\text { preserved ejection } \\
\text { fraction }\end{array}$ & $\begin{array}{l}\text { Ameliorate diastolic dysfunction, and } \\
\text { attenuate cardiac inflammation and } \\
\text { fibrosis }\end{array}$ \\
\hline & $\begin{array}{l}\text { Nasi-Er et al. } \\
(2019)\end{array}$ & Dogs & Bilateral Ears & $50 \%$ of the threshold voltage & $\begin{array}{l}\text { Acute myocardial } \\
\text { infarction }\end{array}$ & $\begin{array}{l}\text { Attenuate electrophysiological } \\
\text { changes and ventricular structural } \\
\text { remodeling, inhibit VAs }\end{array}$ \\
\hline & $\begin{array}{l}\text { Stavrakis et al. } \\
(2015)\end{array}$ & Patients & Ear & & & \\
\hline & Yu et al. (2017c) & Patients & Ear & $\begin{array}{l}50 \% \text { lower than the electric } \\
\text { current that slowed the sinus } \\
\text { rate }\end{array}$ & $\begin{array}{l}\text { Ischemia reperfusion } \\
\text { injury }\end{array}$ & $\begin{array}{l}\text { Reduce VAs } \\
\text { Attenuate cardiac function }\end{array}$ \\
\hline \multirow[t]{2}{*}{$\begin{array}{l}\text { Magnetic field } \\
\text { stimulation }\end{array}$} & Wang et al. (2016) & Canine & $\begin{array}{l}\text { Left stellate } \\
\text { ganglion }\end{array}$ & $\begin{array}{l}1 \mathrm{HZ} \text {; stimulation time } 8 \mathrm{~s} \text {; } \\
\text { interstimulus interval, } 5 \mathrm{~s}\end{array}$ & $\begin{array}{l}\text { Acute myocardial } \\
\text { infarction }\end{array}$ & Inhibit LSG activity and VAs \\
\hline & $\begin{array}{l}\text { Nishikawa et al. } \\
\text { (2017) }\end{array}$ & Patients & $\begin{array}{l}\text { Right cervical } \\
\text { vagus nerve }\end{array}$ & $\begin{array}{l}\text { Frequency } 5 \text { or } 20 \mathrm{~Hz} \text {, pulse } \\
\text { to } 250 \text { us }\end{array}$ & Healthy & $\begin{array}{l}\text { No side effects without bradycardia } \\
\text { and arterial pressure changes }\end{array}$ \\
\hline $\begin{array}{l}\text { Ultrasonic } \\
\text { stimulation }\end{array}$ & $\begin{array}{l}\text { Wang et al. } \\
\text { (2019a) }\end{array}$ & Dogs & LSG & $\begin{array}{l}\text { Frequency } 1 \mathrm{MHz} \text {, Pulse } \\
\text { repetition frequency } 1 \mathrm{KHz} \text {, } \\
\text { Duty cycle } 8 \text { s, Duty cycle \% } \\
50 \%\end{array}$ & $\begin{array}{l}\text { Acute myocardial } \\
\text { infarction }\end{array}$ & Suppress LSG activity and VAs \\
\hline $\begin{array}{l}\text { Optogenetic } \\
\text { stimulation }\end{array}$ & Yu et al. (2017d) & Canine & LSG & $\begin{array}{l}\text { Light-emitting diode } \\
\text { illumination ( } 565 \text { nm) }\end{array}$ & Myocardial infarction & Inhibit LSG activety and VAs \\
\hline \multirow[t]{2}{*}{$\begin{array}{l}\text { Light-emitting } \\
\text { diode }\end{array}$} & $\begin{array}{l}\text { Wang et al. } \\
\text { (2019b) }\end{array}$ & Rats & Brain & $\begin{array}{l}\text { Peak wavelength, } 610 \mathrm{~nm} \text {; } \\
\text { power intensity, } 1.7 \mathrm{~mW} / \mathrm{cm}^{2} \text {; } \\
\text { energy density, } 2.0 \mathrm{~J} / \mathrm{cm}^{2}\end{array}$ & $\begin{array}{l}\text { Acute myocardial } \\
\text { infarction }\end{array}$ & $\begin{array}{l}\text { Inhibit LSG activity and VAs. Reduce } \\
\text { inflammation }\end{array}$ \\
\hline & $\begin{array}{l}\text { Wang et al. } \\
\text { (2019c) }\end{array}$ & Rats & Brain & $\begin{array}{l}\text { Peak wavelength, } 610 \mathrm{~nm} \text {; } \\
\text { power intensity, } 1.7 \mathrm{~mW} / \mathrm{cm}^{2} \text {; } \\
\text { energy density, } 2.0 \mathrm{~J} / \mathrm{cm}^{2}\end{array}$ & $\begin{array}{l}\text { Acute myocardial } \\
\text { ischemia reperfusion } \\
\text { injury }\end{array}$ & $\begin{array}{l}\text { Inhibit LSG activity and VAs. Reduce } \\
\text { inflammation }\end{array}$ \\
\hline
\end{tabular}

LSG, left stellate ganglion; MMP, matrix metalloproteinase; RSG, right stellate ganglion; TGF, transforming growth factor; VAs, ventricular arrhythmias.

(LL-VNS) has been proven to suppress AF (Zhang et al., 2009; Sheng et al., 2011; Shen et al., 2013). Low-level ta-VNS (LLta-VNS) has the same effect as LL-VNS. Yu et al. (2013) first reported that LL-ta-VNS could reverse RAP-induced atrial remodeling and inhibit AF inducibility in canine models. This indicates that LL-ta-VNS is a potential non-invasive approach for AF treatment. We further found that LL-ta-VNS inhibited AF by modulating the expression of atrial connexin 40 and connexin 43 (Chen et al., 2015c,d). Later, Stavrakis et al. (2015, 2017) showed that LL-ta-VNS suppressed AF and decreased inflammatory cytokines in patients with paroxysmal AF in a clinical study.
Later, they continued to conduct a TREAT AF trial to prove the long-term effect of LL-ta-VNS.

Beyond its atrial protective effects, LL-ta-VNS has also been applied to research left ventricular remodeling and arrhythmias. Wang et al. (2014) and Wang Z. et al. (2015) showed that chronic intermittent LL-ta-VNS could attenuate left ventricular remodeling in conscious dogs with healed myocardial infarction. It demonstrated ventricular protection against ta-VNS. Chronic LL-ta-VNS could reduce the inducibility of ventricular arrhythmia, LSG neural activity, and sympathetic neural remodeling in a post-infarction canine model. Downregulation 


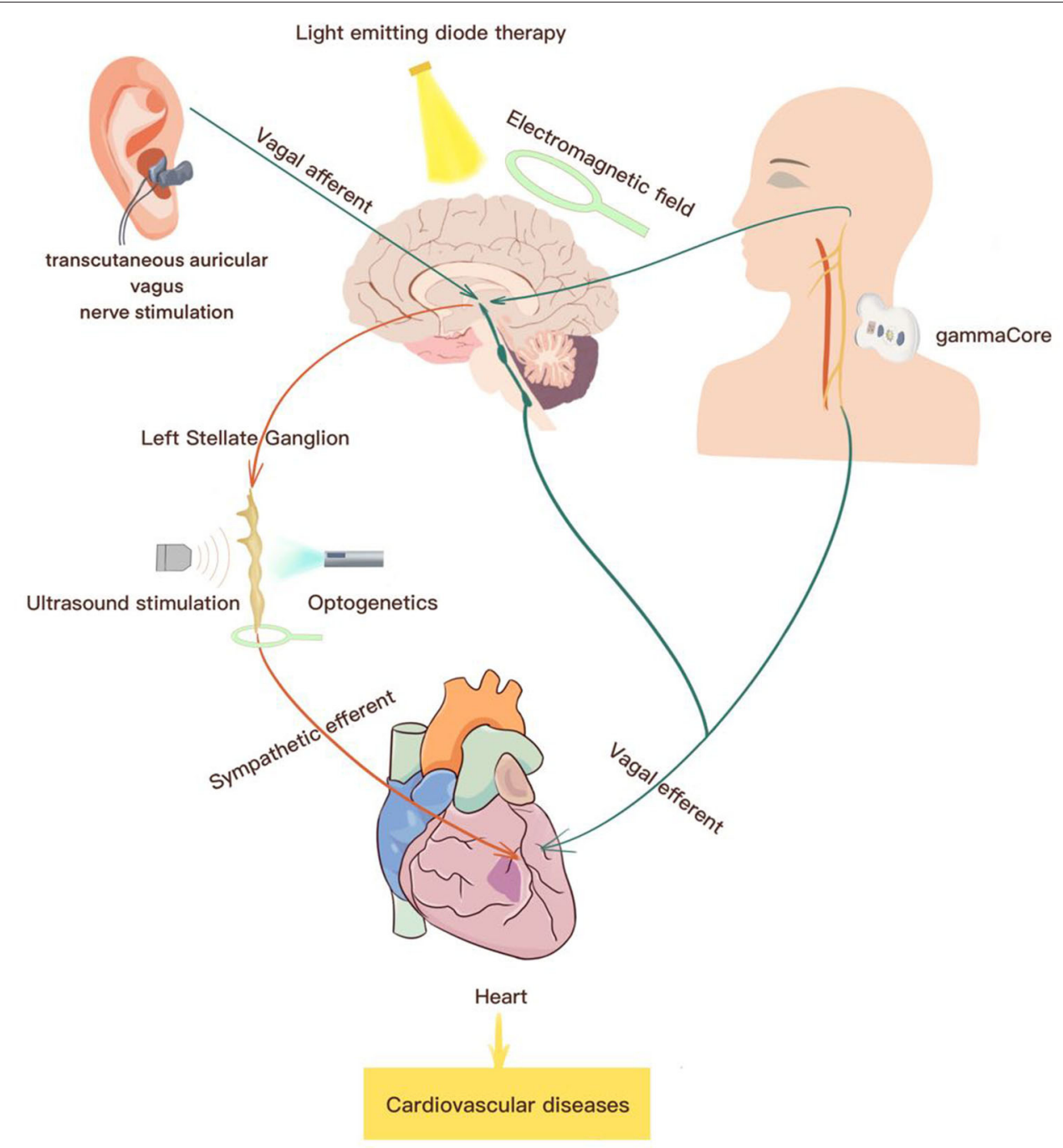

FIGURE 2 | Summary of potential non-invasive neuromodulations for the treatment of cardiovascular diseases. Current therapeutic strategies for the treatment of cardiovascular diseases include transcutaneous auricular vagus nerve stimulation, electromagnetic field stimulation, ultrasound stimulation, optogenetics for stimulation, transcutaneous cervical nerve stimulation.

of nerve growth factor protein and upregulation of SK2 protein in the LSG contributed to the salutary effects of LL-ta-VNS (Yu et al., 2016). Nasi-Er et al. also demonstrated that TS reduced the occurrence of spontaneous ventricular arrhythmias in conscious dogs with MI. The potential mechanisms of anti-ventricular arrhythmias may increase ventricular electrical stability and alleviate ventricular interstitial fibrosis (Nasi-Er et al., 2019). In a recent patient study, Yu et al. (2017c) found that LL-taVNS reduced the incidence of reperfusion-related ventricular arrhythmias during the first $24 \mathrm{~h}$ after acute myocardial infarction and improved left ventricular function 5-7 days after reperfusion along with reduced venous cytokine levels.

Sympathetic activity can regulate sinus node acceleration. Zhou et al. (2016) performed a study and showed that rightsided ta-VNS could inhibit sinus node acceleration induced by sympathetic nerves. Its potential mechanism may suppress right-sided stellate ganglion activity by modulating SK2, c-fos, and nerve growth factor protein expression. Currently, there is limited evidence to prove that drugs can improve the outcomes of heart failure with preserved ejection fraction. Interestingly, Po et al. also demonstrated that LL-ta-VNS could effectively treat heart failure with preserved ejection fraction in a rat model. It attenuated cardiac remodeling by inhibiting left ventricular fibrosis and inflammatory cell infiltration (Zhou et al., 2019). However, further trials are needed to study and support the observed beneficial effects in clinical settings.

However, because of the absence of standards regarding stimulation protocols, the parameters of ta-VNS have not been used consistently in research (Borges et al., 2019). Several studies have not shown positive effects of ta-VNS on vagal-related heart rate viability. The heterogeneous results may be due to the use of different stimulation parameters, differing in electrode placement 
areas on the ear, pulse width, frequency, and on-off cycle (Burger et al., 2016, 2017, 2019; De Couck et al., 2017).

\section{Electromagnetic Fields in the CANS and Cardiovascular Diseases}

Electromagnetic waves are waves caused by vibrations between an electric field and a magnetic field. Electromagnetic waves transfer energy to tissues, resulting in functional changes or structural damage. Electromagnetic fields (EMFs) were first explored for use in diagnosing human diseases. In recent years, because of their non-invasive and safe advantages, EMFs have been developed and applied to treat a wide range of diseases, such as nervous system disorders, cardiovascular diseases, diabetes, spinal cord injuries, ulcers, and asthma (Schestatsky et al., 2013; Cabrerizo et al., 2014; Vernieri et al., 2014; Chervyakov et al., 2015).

Interestingly, EMF exposure can affect the structure and modulate the function of the ANS. EMFs can significantly change the physiological properties of the CANS neural network by the results of some ionic flux changes. A study showed that EMF exposure could increase sympathetic vasoconstrictor activity (Braune et al., 2002). Different parameters (frequencies and amplitudes) of stimulation contribute to different results. Recently, Wang et al. (2016) showed that EMF stimulation located on the surface of the left stellate ganglion could effectively reduce sympathetic activity and the incidence of ventricular arrhythmias in myocardial infarction canine models. EMF stimulation was applied with low frequency $(1 \mathrm{~Hz}$, intensity at $\sim 90 \%$ of the motor threshold; $8 \mathrm{~s}$ on, $10 \mathrm{~s}$ off). EMF stimulation of the left stellate ganglion is a novel therapeutic strategy for treating ventricular arrhythmias associated with autonomic imbalance. Among EMFs for the vagus nerve, Nishikawa et al. (2017) found that EMFs could induce transient heart rate reduction in some healthy individuals but failed to induce sustained bradycardia and arterial pressure changes. This indicates that the magnetic focus and optimized stimulation need further improvement for beneficial effects in acute myocardial infarction. Scherlag et al. used a low-frequency electromagnetic field (LL-EMF) to expose the chest for $35 \mathrm{~min}$ in canine AF models and found that LL-EMF could successfully inhibit AF for 3-4h (Yu et al., 2015). As is well-known, pericardial fat pads, including ganglion plexi, exist in high numbers on the surface of the heart. Whether LL-EMFs suppress AF by affecting the ganglion plexus remains unknown. There is still a need for further studies to prove this influence.

EMFs have the advantages of simplicity, low operating costs, and unproven harmful effects. EMFs show promising potential in the treatment of cardiovascular diseases by autonomic neuromodulation.

\section{Ultrasound Stimulation of the CANS and Cardiovascular Diseases}

In the 1950s, ultrasound was applied to visualize tissue structure for diagnostic applications (Edler and Lindstrom, 2004). Ultrasound was also used for therapeutic indications as an ablative approach for the treatment of Parkinson's disease in earlier decades (Leinenga et al., 2016). Therapeutic ultrasound stimulation technologies are currently approved by the United States Food and Drug Administration (FDA) and used for the treatment of multiple diseases. Ultrasound stimulation parameters (frequency, amplitude, pulse duration) can be optimized for therapeutic or diagnostic applications (Downs et al., 2018). Ultrasound waves are transmitted into tissues. A portion of the waves are converted into thermal energy. Ultrasound waves affect tissues via thermal and non-thermal mechanisms. The functional changes in tissues are decided by the frequency and intensity of the ultrasound waves (dosage) and the types of tissues that are exposed to ultrasound. Ultrasound stimulation of the neural system as acoustic neuromodulation has received great interest due to its non-invasive advantage (Kim et al., 2014).

Ultrasound neuromodulation can stimulate or inhibit neural structures, which can be classified as central nervous system or peripheral nervous system influences. Transcranial ultrasound stimulation can target special brain regions and modulate specific neuronal pathways or nuclei. It has been widely researched in basic neuroscience and has been recommended as a potential therapy for neurological diseases (Bystritsky et al., 2011). In terms of the focus on the peripheral nervous system, Wasilczuk et al. (2019) observed that low-intensity focused ultrasound stimulation of the vagus nerve exerted anti-inflammatory effects and significantly reduced tumor factor necrosis- $\alpha$ levels. Recently, ultrasound-induced neuromodulation has gained interest due to its potential to non-invasively modulate ANS activity for the treatment of cardiovascular diseases. Wang et al. (2019a) showed that low-intensity ultrasound stimulation reduced ventricular arrhythmias by modulating sympathetic neural activity in a myocardial infarction canine model.

\section{Optogenetics in Autonomic Neuromodulation for Cardiovascular Diseases}

In 2006, Deisseroth et al. first referred to the word "optogenetics" (Deisseroth et al., 2006). Optogenetics offers a technique to control and monitor the activity of excitable cells by light. This method genetically affects the expression of light-sensitive ion channels, known as opsins, to achieve precise control of targeted cell activity (Deisseroth, 2011). Recently, optogenetics has been widely developed and used in the field of neuroscience and cardiac tissues to control the activity of specific neuron and myocardial populations. It has been applied for the treatment of neurological disorders in experiments (Boyden, 2015). Optogenetics also contributes to further explaining the mechanisms of the initiation, perpetuation, and termination of arrhythmias in cardiac areas (Nussinovitch and Gepstein, 2015; Vogt et al., 2015; Hulsmans et al., 2017).

More recently, optogenetics has enabled the spatially and temporally specific stimulation of cardiac autonomic neurons using light. Photostimulation of neurons expressing the lightgated cation channel channelrhodopsin modulates cardiac autonomic nerve activity and then evaluates the potential cardiovascular changes (Wengrowski et al., 2015; Yamamoto et al., 2015; Gepstein and Gruber, 2017). 
Optogenetics selectively stimulates the cardiac ANS by the release of acetylcholine or norepinephrine (Abbott et al., 2013). Yu et al. (2017d) first applied optogenetics to regulate the activity of the left stellate ganglion to prevent ventricular arrhythmias induced by acute myocardial infarction in canine models. Virus was transfected into left stellate ganglion neurons to induce the expression of ArchT proteins. Proper illumination (565 nm) activated ArchT and caused hyperpolarizing currents in the neurons. Optogenetics reversibly suppressed the cardiac sympathetic tone and then exerted a protective role against ventricular arrhythmias associated with autonomic nerve dysfunction.

\section{Light-Emitting Diode Therapy in the Modulation of the CANS for Cardiovascular Diseases}

In the late 1960s, light-emitting diode (LED) therapy was first discovered ( $\mathrm{Li}$ et al., 2013). LED therapy has been recently introduced into medicine and widely applied in dermatology. LED photomodulation is a non-thermal technology used to modulate cellular activity with light, and photons are absorbed by mitochondrial chromophores in cells. It has been reported that low-intensity LED phototherapy has various protective effects, including inhibiting the inflammatory response and increasing collagen synthesis. Because of the non-invasive therapy with side effects reported in the published literature, LED therapy has gradually been applied in cardiovascular diseases (Gold, 2011; Avci et al., 2014; Capalonga et al., 2016; Sorbellini et al., 2018).

Recently, Wang et al. (2019b) reported that LED therapy reduced post-infarction ventricular arrhythmias by modulating the neuroimmune network. In this study, LED therapy significantly suppressed the activity of the left stellate ganglion and reduced the levels of pro-inflammatory cytokines through the inhibition of microglial activation in the hypothalamic paraventricular nucleus. LED therapy might reduce myocardial ischemia/reperfusion-induced ventricular arrhythmias by attenuating microglial and sympathetic over-activation. They also proved that LED therapy has the same indirect effects of sympathetic activity in a rat model of acute myocardial ischemia/reperfusion injury (Wang et al., 2019c). This indicates that LED affects the ANS through the inhibition of inflammation rather than through direct effects. Currently, there is no evidence to prove that LED can directly activate ANS.

\section{gammaCore (Non-invasive Cervical Vagus Nerve Stimulation) and Cardiovascular Diseases}

gammaCore, a non-invasive cervical vagus nerve stimulator, is already an FDA-approved device for the treatment of primary headache disorders. It is used by sending mild electrical stimulation through the skin to activate the vagus nerve from outside the body. It is programmed for stimulation in cycles for $2 \mathrm{~min}$, and one treatment consists of three cycles (Akdemir and Benditt, 2016; Mwamburi et al., 2017).

This kind of non-invasive neuromodulation has been used to treat cluster headaches (Simon and Blake, 2017). Current clinical evidence shows that gammaCore can reduce the frequency and intensity of cluster headache attacks in some patients (Tassorelli et al., 2018). It can also reduce the need for medication. This is likely to lead to significant quality of life benefits for people living with this condition.

gammaCore $^{\mathrm{TM}}$ is a simple-to-use, handheld medical device that enables patients to self-administer discrete doses of noninvasive vagus nerve stimulation (nVNS) therapy. Cost analysis suggests that using gammaCore may lead to cost savings (Mwamburi et al., 2018). However, there is no evidence for the treatment of cardiovascular diseases by gammaCore ${ }^{\mathrm{TM}}$. The effect of gammaCore ${ }^{\mathrm{TM}}$ on the treatment of cardiovascular diseases needs further study in both experimental and clinical areas. It is an emerging and potential type of neuromodulation for the treatment of cardiovascular diseases.

\section{POTENTIAL OPPORTUNITIES AND CHALLENGES}

Non-invasive neuromodulation provides opportunities for better understanding ANS circuits and neurophysiological responses (Boes et al., 2018). It also provides a potential therapeutic target for the treatment of cardiovascular diseases. These kinds of neuromodulation are usually low-cost, portable, and easy to use. Due to the novel and non-invasive approach, it is an attractive therapy for clinical doctors. Patients with non-invasive neuromodulations maybe have a better compliance. Clinical doctor can wirelessly re-set up parameters when patients with chronic pain or movement disorder at home. Non-invasive neuromodulation of the ANS has opened new frontiers for the application of cardiovascular disorders.

However, the road of non-invasive neuromodulations translation in cardiovascular diseases, the same as invasive neuromodulations, is also not flat. There is still a long way to go to translate clinical application to treatment of cardiovascular diseases. For example, divergent results also exist. A doseresponse curve is estimated to determine the proper dosage and achieve the most probable benefit in pharmacological trials (Mann and Deswal, 2003). It should also be recommended for invasive and non-invasive neuromodulation (Zannad et al., 2015; Byku and Mann, 2016; DiCarlo et al., 2018). The efficacy of non-invasive neuromodulation might be variable. Multiple reasons might be responsible for the divergent results, including individual differences, protocol parameters (current intensity, frequency, duty cycle), and failure to engage the appropriate neurobiological target. To optimize efficacy and preserve safety, further basic research and clinical studies need to be performed to assess the long-term effects of non-invasive neuromodulation.

\section{CONCLUSIONS}

Autonomic dysfunction plays an important role in the process of cardiovascular disorders. Neuromodulation has been proven to be an emerging non-pharmacological approach for the treatment of cardiovascular diseases in basic research and clinical studies. Based on anatomy and nerve denervation, neurostimulation approaches are divided into invasive and non-invasive approaches. Invasive neuromodulation approaches 
are usually hampered by the potential risks of complications, side effects, increases in electrical impedance, and even perpetual nerve damage. Recently, non-invasive neuromodulation approaches have received great interest in the treatment of cardiovascular diseases. However, due to the limited evidence, further experimental studies and clinical trials are still needed.

\section{DATA AVAILABILITY STATEMENT}

The raw data supporting the conclusions of this article will be made available by the authors, without undue reservation.

\section{AUTHOR CONTRIBUTIONS}

MC, XL, and SW participated in the study design and drafted the manuscript. SZ and MC were responsible

\section{REFERENCES}

Abbott, S. B., DePuy, S. D., Nguyen, T., Coates, M. B., Stornetta, R. L., and Guyenet, P. G. (2013). Selective optogenetic activation of rostral ventrolateral medullary catecholaminergic neurons produces cardiorespiratory stimulation in conscious mice. J. Neurosci. 33, 3164-3177. doi: 10.1523/JNEUROSCI.1046-12.2013

Akdemir, B., and Benditt, D. G. (2016). Vagus nerve stimulation: An evolving adjunctive treatment for cardiac disease. Anatol. J. Cardiol. 16, 804-810. doi: 10.14744/AnatolJCardiol.2016.7129

Avci, P., Gupta, G. K., Clark, J., Wikonkal, N., and Hamblin, M. R. (2014). Lowlevel laser (light) therapy (LLLT) for treatment of hair loss. Lasers Surg. Med. 46, 144-151. doi: 10.1002/lsm.22170

Boes, A. D., Kelly, M. S., Trapp, N. T., Stern, A. P., Press, D. Z., and PascualLeone, A. (2018). Noninvasive brain stimulation: challenges and opportunities for a new clinical specialty. J. Neuropsychiatry Clin. Neurosci. 30, 173-179. doi: 10.1176/appi.neuropsych.17110262

Borges, U., Laborde, S., and Raab, M. (2019). Influence of transcutaneous vagus nerve stimulation on cardiac vagal activity: not different from sham stimulation and no effect of stimulation intensity. PLOS ONE 14:e0223848. doi: 10.1371/journal.pone.0223848

Boyden, E. S. (2015). Optogenetics and the future of neuroscience. Nat. Neurosci. 18, 1200-1201. doi: 10.1038/nn.4094

Brack, K. E. (2015). The heart's 'little brain' controlling cardiac function in the rabbit. Exp. Physiol. 100, 348-353. doi: 10.1113/expphysiol.2014.080168

Braune, S., Riedel, A., Schulte-Monting, J., and Raczek, J. (2002). Influence of a radiofrequency electromagnetic field on cardiovascular and hormonal parameters of the autonomic nervous system in healthy individuals. Radiat. Res. 158, 352-356. doi: 10.1667/0033-7587(2002)158[0352:IOAREF]2.0.CO;2

Burger, A. M., Van der Does, W., Thayer, J. F., Brosschot, J. F., and Verkuil, B. (2019). Transcutaneous vagus nerve stimulation reduces spontaneous but not induced negative thought intrusions in high worriers. Biol. Psychol. 142, 80-89. doi: 10.1016/j.biopsycho.2019.01.014

Burger, A. M., and Verkuil, B. (2018). Transcutaneous nerve stimulation via the tragus: are we really stimulating the vagus nerve? Brain Stimul. 11, 945-946. doi: 10.1016/j.brs.2018.03.018

Burger, A. M., Verkuil, B., Fenlon, H., Thijs, L., Cools, L., Miller, H. C., et al. (2017). Mixed evidence for the potential of non-invasive transcutaneous vagal nerve stimulation to improve the extinction and retention of fear. Behav. Res. Ther. 97, 64-74. doi: 10.1016/j.brat.2017.07.005

Burger, A. M., Verkuil, B., Van Diest, I., Van der Does, W., Thayer, J. F., and Brosschot, J. F. (2016). The effects of transcutaneous vagus nerve stimulation on conditioned fear extinction in humans. Neurobiol. Learn. Mem. 132, 49-56. doi: 10.1016/j.nlm.2016.05.007 for writing the manuscript. LY, QL, and JT participated in the overall editing and approval of the paper. All authors contributed to the article and approved the submitted version.

\section{FUNDING}

Financial support was obtained from the National Natural Science Foundation of China Nos. 81270257 and 81800302 and Provincial Natural Science Foundation of Hunan No. 2019JJ50871.

\section{ACKNOWLEDGMENTS}

The authors would like to thank Minjia Xiao and Jiaying Liao for modification.

Byku, M., and Mann, D. L. (2016). Neuromodulation of the failing heart: lost in translation? JACC Basic Transl. Sci. 1, 95-106. doi: 10.1016/j.jacbts.2016.03.004

Bystritsky, A., Korb, A. S., Douglas, P. K., Cohen, M. S., Melega, W. P., Mulgaonkar, A. P., et al. (2011). A review of low-intensity focused ultrasound pulsation. Brain Stimul. 4, 125-136. doi: 10.1016/j.brs.2011. 03.007

Cabrerizo, M., Cabrera, A., Perez, J. O., de la Rua, J., Rojas, N., Zhou, Q., et al. (2014). Induced effects of transcranial magnetic stimulation on the autonomic nervous system and the cardiac rhythm. ScientificWorldJournal 2014:349718. doi: $10.1155 / 2014 / 349718$

Capalonga, L., Karsten, M., Hentschke, V. S., Rossato, D. D., Dornelles, M. P., Sonza, A., et al. (2016). Light-emitting diode therapy (LEDT) improves functional capacity in rats with heart failure. Lasers Med. Sci. 31, 937-944. doi: 10.1007/s10103-016-1922-y

Cha, Y. M., Li, X., Yang, M., Han, J., Wu, G., Kapa, S. C., et al. (2019). Stellate ganglion block and cardiac sympathetic denervation in patients with inappropriate sinus tachycardia. J. Cardiovasc. Electrophysiol. 30, 2920-2928. doi: $10.1111 /$ jce. 14233

Chen, M., Li, X., Yang, H., Tang, J., and Zhou, S. (2019). Hype or hope: vagus nerve stimulation against acute myocardial ischemia-reperfusion injury. Trends Cardiovasc. Med. doi: 10.1016/j.tcm.2019.10.011

Chen, M., Yu, L., Liu, Q., Wang, Z., Wang, S., Jiang, H., et al. (2015c). Low level tragus nerve stimulation is a non-invasive approach for anti-atrial fibrillation via preventing the loss of connexins. Int. J. Cardiol. 179, 144-145. doi: 10.1016/j.ijcard.2014.10.114

Chen, M., Yu, L., Liu, Q., Wang, Z., Wang, S., Zhou, L., et al. (2015a). Noninvasive vagus nerve stimulation: a novel promising modulator for cardiac autonomic nerve system dysfunction. Int. J. Cardiol. 187, 338-339. doi: 10.1016/j.ijcard.2015.03.317

Chen, M., Yu, L., Zhou, X., Liu, Q., Jiang, H., and Zhou, S. (2015b). Low-level vagus nerve stimulation: an important therapeutic option for atrial fibrillation treatment via modulating cardiac autonomic tone. Int. J. Cardiol. 199, 437-438. doi: 10.1016/j.ijcard.2015.07.083

Chen, M., Zhou, X., Liu, Q., Sheng, X., Yu, L., Wang, Z., et al. (2015d). Leftsided noninvasive vagus nerve stimulation suppresses atrial fibrillation by upregulating atrial gap junctions in canines. J. Cardiovasc. Pharmacol. 66, 593-599. doi: 10.1097/FJC.0000000000000309

Chen, M., Zhou, X., Yu, L., Liu, Q., Sheng, X., Wang, Z., et al. (2016). Low-level vagus nerve stimulation attenuates myocardial ischemic reperfusion injury by antioxidative stress and antiapoptosis reactions in canines. J. Cardiovasc. Electrophysiol. 27, 224-231. doi: 10.1111/jce.12850

Chen, P. S., Chen, L. S., Fishbein, M. C., Lin, S. F., and Nattel, S. (2014). Role of the autonomic nervous system in atrial fibrillation: pathophysiology and therapy. Circ. Res. 114, 1500-1515. doi: 10.1161/CIRCRESAHA.114.303772 
Chervyakov, A. V., Chernyavsky, A. Y., Sinitsyn, D. O., and Piradov, M. A. (2015). Possible mechanisms underlying the therapeutic effects of transcranial magnetic stimulation. Front. Hum. Neurosci. 9:303. doi: 10.3389/fnhum.2015.00303

Clancy, J. A., Mary, D. A., Witte, K. K., Greenwood, J. P., Deuchars, S. A., and Deuchars, J. (2014). Non-invasive vagus nerve stimulation in healthy humans reduces sympathetic nerve activity. Brain Stimul. 7, 871-877. doi: 10.1016/j.brs.2014.07.031

Cook, I. A., Espinoza, R., and Leuchter, A. F. (2014). Neuromodulation for depression: invasive and noninvasive (deep brain stimulation, transcranial magnetic stimulation, trigeminal nerve stimulation). Neurosurg. Clin. North Am. 25, 103-116. doi: 10.1016/j.nec.2013.10.002

Cotero, V., Fan, Y., Tsaava, T., Kressel, A. M., Hancu, I., Fitzgerald, P., et al. (2019). Noninvasive sub-organ ultrasound stimulation for targeted neuromodulation. Nat. Commun. 10:952. doi: 10.1038/s41467-019-08750-9

De Couck, M., Cserjesi, R., Caers, R., Zijlstra, W. P., Widjaja, D., Wolf, N., et al. (2017). Effects of short and prolonged transcutaneous vagus nerve stimulation on heart rate variability in healthy subjects. Auton. Neurosci. 203, 88-96. doi: 10.1016/j.autneu.2016.11.003

Deisseroth, K. (2011). Optogenetics. Nat. Methods 8, 26-29. doi: 10.1038/nmeth.f.324

Deisseroth, K., Feng, G., Majewska, A. K., Miesenbock, G., Ting, A., and Schnitzer, M. J. (2006). Next-generation optical technologies for illuminating genetically targeted brain circuits. J. Neurosci. 26, 10380-10386. doi: 10.1523/JNEUROSCI.3863-06.2006

DiCarlo, L. A., Libbus, I., Kumar, H. U., Mittal, S., Premchand, R. K., Amurthur, B., et al. (2018). Autonomic regulation therapy to enhance myocardial function in heart failure patients: the ANTHEM-HFpEF study. ESC Heart Fail. 5, 95-100. doi: $10.1002 /$ ehf2.12241

Doruk Camsari, D., Kirkovski, M., and Croarkin, P. E. (2018). Therapeutic applications of invasive neuromodulation in children and adolescents. Psychiatr. Clin. North Am. 41, 479-483. doi: 10.1016/j.psc.2018.04.008

Downs, M. E., Lee, S. A., Yang, G., Kim, S., Wang, Q., and Konofagou, E. E. (2018). Non-invasive peripheral nerve stimulation via focused ultrasound in vivo. Phys. Med. Biol. 63:035011. doi: 10.1088/1361-6560/aa9fc2

Edler, I., and Lindstrom, K. (2004). The history of echocardiography. Ultrasound Med. Biol. 30, 1565-1644. doi: 10.1016/S0301-5629(99)00056-3

Eldabe, S., Buchser, E., and Duarte, R. V. (2016). Complications of spinal cord stimulation and peripheral nerve stimulation techniques: a review of the literature. Pain Med. 17, 325-336. doi: 10.1093/pm/pnv025

Gepstein, L., and Gruber, A. (2017). Optogenetic neuromodulation of the heart. J. Am. Coll. Cardiol. 70, 2791-2794. doi: 10.1016/j.jacc.2017. 10.003

Gold, M. H. (2011). Light-emitting diode. Curr. Probl. Dermatol. 42, 173-180. doi: $10.1159 / 000328326$

Hulsmans, M., Clauss, S., Xiao, L., Aguirre, A. D., King, K. R., Hanley, A., et al. (2017). Macrophages facilitate electrical conduction in the heart. Cell. 169, 510-522 e20. doi: 10.1016/j.cell.2017.03.050

Kaniusas, E., Kampusch, S., Tittgemeyer, M., Panetsos, F., Gines, R. F., Papa, M., et al. (2019a). Current directions in the auricular vagus nerve stimulation II-an engineering perspective. Front. Neurosci. 13:772. doi: 10.3389/fnins.2019.00772

Kaniusas, E., Kampusch, S., Tittgemeyer, M., Panetsos, F., Gines, R. F., Papa, M., et al. (2019b). Current directions in the auricular vagus nerve stimulation I-a physiological perspective. Front. Neurosci. 13:854. doi: 10.3389/fnins.2019.00854

Kim, H., Chiu, A., Lee, S. D., Fischer, K., and Yoo, S. S. (2014). Focused ultrasound-mediated non-invasive brain stimulation: examination of sonication parameters. Brain Stimul. 7, 748-756. doi: 10.1016/j.brs.2014.06.011

Lai, Y., Yu, L., and Jiang, H. (2019). Autonomic neuromodulation for preventing and treating ventricular arrhythmias. Front. Physiol. 10:200. doi: 10.3389 /fphys. 2019.00200

Leinenga, G., Langton, C., Nisbet, R., and Gotz, J. (2016). Ultrasound treatment of neurological diseases-current and emerging applications. Nat. Rev. Neurol. 12, 161-174. doi: 10.1038/nrneurol.2016.13

Levy, R., Henderson, J., Slavin, K., Simpson, B. A., Barolat, G., Shipley, J., et al. (2011). Incidence and avoidance of neurologic complications with paddle type spinal cord stimulation leads. Neuromodulation 14, 412-422; discussion 22. doi: $10.1111 / j .1525-1403.2011 .00395 . x$
Levy, R. M. (2013). Device complication and failure management in neuromodulation. Neuromodulation 16, 495-502. doi: 10.1111/ner.12148

Li, N., Oida, S., Tulevski, G. S., Han, S. J., Hannon, J. B., Sadana, D. K., et al. (2013). Efficient and bright organic light-emitting diodes on single-layer graphene electrodes. Nat. Commun. 4:2294. doi: 10.1038/ncomms3294

Lohmeier, T. E., and Hall, J. E. (2019). Device-based neuromodulation for resistant hypertension therapy. Circ. Res. 124, 1071-1093. doi: 10.1161/CIRCRESAHA.118.313221

Lopshire, J. C., and Zipes, D. P. (2014). Spinal cord stimulation for heart failure: preclinical studies to determine optimal stimulation parameters for clinical efficacy. J. Cardiovasc. Transl. Res. 7, 321-329. doi: 10.1007/s12265-014-9547-7

Lotti, F., Ranieri, F., Vadala, G., Zollo, L., and Di Pino, G. (2017). Invasive intraneural interfaces: foreign body reaction issues. Front. Neurosci. 11:497. doi: 10.3389 /fnins.2017.00497

Mann, D. L., and Deswal, A. (2003). Angiotensin-receptor blockade in acute myocardial infarction-a matter of dose. N. Engl. J. Med. 349, 1963-1965. doi: 10.1056/NEJMe038163

Mwamburi, M., Liebler, E. J., and Tenaglia, A. T. (2017). Review of non-invasive vagus nerve stimulation (gammaCore): efficacy, safety, potential impact on comorbidities, and economic burden for episodic and chronic cluster headache. Am. J. Manag. Care 23, S317-S325.

Mwamburi, M., Tenaglia, A. T., Leibler, E. J., and Staats, P. S. (2018). Costeffectiveness of noninvasive vagus nerve stimulation for acute treatment of episodic migraine and role in treatment sequence strategies. Am. J. Manag. Care 24, S527-S533.

Nasi-Er, B. G., Wenhui, Z., HuaXin, S., Xianhui, Z., Yaodong, L., Yanmei, L., et al. (2019). Vagus nerve stimulation reduces ventricular arrhythmias and increases ventricular electrical stability. Pacing Clin. Electrophysiol. 42, 247-256. doi: 10.1111/pace. 13585

Nishikawa, T., Saku, K., Todaka, K., Kuwabara, Y., Arai, S., Kishi, T., et al. (2017). The challenge of magnetic vagal nerve stimulation for myocardial infarction preliminary clinical trial. Conf. Proc. IEEE Eng. Med. Biol. Soc. 2017, 4321-4324. doi: 10.1109/EMBC.2017.8037812

Nussinovitch, U., and Gepstein, L. (2015). Optogenetics for in vivo cardiac pacing and resynchronization therapies. Nat. Biotechnol. 33, 750-754. doi: $10.1038 /$ nbt.3268

Olshansky, B. (2016). Vagus nerve modulation of inflammation: cardiovascular implications. Trends Cardiovasc. Med. 26, 1-11. doi: 10.1016/j.tcm.2015.03.016

Petraglia, F. W. III, Farber, S. H., Gramer, R., Verla, T., Wang, F., Thomas, S., et al. (2016). The incidence of spinal cord injury in implantation of percutaneous and paddle electrodes for spinal cord stimulation. Neuromodulation 19, 85-90. doi: 10.1111/ner.12370

Redgrave, J., Day, D., Leung, H., Laud, P. J., Ali, A., Lindert, R., et al. (2018). Safety and tolerability of transcutaneous vagus nerve stimulation in humans; a systematic review. Brain Stimul. 11, 1225-1238. doi: 10.1016/j.brs.2018.08.010

Ricardo, J. A., and Koh, E. T. (1978). Anatomical evidence of direct projections from the nucleus of the solitary tract to the hypothalamus, amygdala, and other forebrain structures in the rat. Brain Res. 153, 1-26. doi: 10.1016/0006-8993(78)91125-3

Ripplinger, C. M., Noujaim, S. F., and Linz, D. (2016). The nervous heart. Prog. Biophys. Mol. Biol. 120, 199-209. doi: 10.1016/j.pbiomolbio.2015.12.015

Roth, G. A., Johnson, C., Abajobir, A., Abd-Allah, F., Abera, S. F., Abyu, G., et al. (2017). Global, regional, and national burden of cardiovascular diseases for 10 causes, 1990 to 2015. J. Am. Coll. Cardiol. 70, 1-25. doi: 10.1016/j.jacc.2017.04.052

Sahyouni, R., Chang, D. T., Moshtaghi, O., Mahmoodi, A., Djalilian, H. R., and Lin, H. W. (2017). Functional and histological effects of chronic neural electrode implantation. Laryngosc. Investig. Otolaryngol. 2, 80-93. doi: 10.1002/lio2.66

Schestatsky, P., Simis, M., Freeman, R., Pascual-Leone, A., and Fregni, F. (2013). Non-invasive brain stimulation and the autonomic nervous system. Clin. Neurophysiol. 124, 1716-1728. doi: 10.1016/j.clinph.2013. 03.020

Schluter, R. S., Daams, J. G., van Holst, R. J., and Goudriaan, A. E. (2018). Effects of non-invasive neuromodulation on executive and other cognitive functions in addictive disorders: a systematic review. Front Neurosci. 12:642. doi: $10.3389 /$ fnins.2018.00642

Shamji, M. F., Westwick, H. J., and Heary, R. F. (2015). Complications related to the use of spinal cord stimulation for managing persistent postoperative 
neuropathic pain after lumbar spinal surgery. Neurosurg. Focus 39:E15. doi: 10.3171/2015.7.FOCUS15260

Shen, M. J., and Zipes, D. P. (2014). Role of the autonomic nervous system in modulating cardiac arrhythmias. Circ. Res. 114, 1004-1021. doi: 10.1161/CIRCRESAHA.113.302549

Shen, X., Scherlag, B. J., He, B., Sun, J., Mei, G., and Po, S. S. (2013). The role of the atrial neural network in atrial fibrillation: the metastatic progression hypothesis. J. Atr. Fibrillation 6:882. doi: 10.4022/jafib.882

Sheng, X., Chen, M., Huang, B., Liu, J., Zhou, L., Bao, M., et al. (2016). Cardioprotective effects of low-level carotid baroreceptor stimulation against myocardial ischemia-reperfusion injury in canine model. J. Interv. Card Electrophysiol. 45, 131-140. doi: 10.1007/s10840-015-0094-1

Sheng, X., Scherlag, B. J., Yu, L., Li, S., Ali, R., Zhang, Y., et al. (2011). Prevention and reversal of atrial fibrillation inducibility and autonomic remodeling by low-level vagosympathetic nerve stimulation. J. Am. Coll. Cardiol. 57, 563-571. doi: 10.1016/j.jacc.2010.09.034

Shiozawa, P., Silva, M. E., Carvalho, T. C., Cordeiro, Q., Brunoni, A. R., and Fregni, F. (2014). Transcutaneous vagus and trigeminal nerve stimulation for neuropsychiatric disorders: a systematic review. Arq. Neuropsiquiatr. 72, 542-547. doi: 10.1590/0004-282X20140061

Simon, B., and Blake, J. (2017). Mechanism of action of non-invasive cervical vagus nerve stimulation for the treatment of primary headaches. Am. J. Manag. Care 23, S312-S316.

Sohinki, D., and Stavrakis, S. (2019). New approaches for treating atrial fibrillation: focus on autonomic modulation. Trends Cardiovasc. Med. 30, 433-439. doi: 10.1016/j.tcm.2019.10.009

Sorbellini, E., Rucco, M., and Rinaldi, F. (2018). Photodynamic and photobiological effects of light-emitting diode (LED) therapy in dermatological disease: an update. Lasers Med. Sci. 33, 1431-1439. doi: $10.1007 / \mathrm{s} 10103-018-2584-8$

Stavrakis, S., Humphrey, M. B., Scherlag, B., Iftikhar, O., Parwani, P., Abbas, M., et al. (2017). Low-level vagus nerve stimulation suppresses post-operative atrial fibrillation and inflammation: a randomized study. JACC Clin. Electrophysiol. 3, 929-938. doi: 10.1016/j.jacep.2017.02.019

Stavrakis, S., Humphrey, M. B., Scherlag, B. J., Hu, Y., Jackman, W. M., Nakagawa, H., et al. (2015). Low-level transcutaneous electrical vagus nerve stimulation suppresses atrial fibrillation. J. Am. Coll. Cardiol. 65, 867-875. doi: 10.1016/j.jacc.2014.12.026

Tassorelli, C., Grazzi, L., de Tommaso, M., Pierangeli, G., Martelletti, P., Rainero, I., et al. (2018). Noninvasive vagus nerve stimulation as acute therapy for migraine: the randomized PRESTO study. Neurology 91, e364-e373. doi: 10.1212/WNL.0000000000005857

Vernieri, F., Altamura, C., Palazzo, P., Altavilla, R., Fabrizio, E., Fini, R., et al. (2014). 1-Hz repetitive transcranial magnetic stimulation increases cerebral vasomotor reactivity: a possible autonomic nervous system modulation. Brain Stimul. 7, 281-286. doi: 10.1016/j.brs.2013.12.014

Vogt, C. C., Bruegmann, T., Malan, D., Ottersbach, A., Roell, W., Fleischmann, B. K., et al. (2015). Systemic gene transfer enables optogenetic pacing of mouse hearts. Cardiovasc. Res. 106, 338-343. doi: 10.1093/cvr/cvv004

Waldron, N. H., Fudim, M., Mathew, J. P., and Piccini, J. P. (2019). Neuromodulation for the treatment of heart rhythm disorders. JACC Basic Transl. Sci. 4, 546-562. doi: 10.1016/j.jacbts.2019.02.009

Wang, S., Li, B., Li, X., Wu, L., and Jiang H (2019a). Low intensity ultrasound stimulation might reduce ventricular arrhythmias by modulation sympathetic neural activity in myocardial infarction canine model. J. Am. Coll. Cardiol. 73:1. doi: 10.1016/S0735-1097(19)31139-8

Wang, S., Li, H., Yu, L., Chen, M., Wang, Z., Huang, B., et al. (2015). Antiarrhythmic effects of atrial ganglionated plexi stimulation is accompanied by preservation of connexin 43 protein in ischemia-reperfusion canine model. Int. J. Clin. Exp. Med. 8, 22098-22107.

Wang, S., Wu, L., Li, X., Li, B., Zhai, Y., Zhao, D., et al. (2019c). Lightemitting diode therapy protects against ventricular arrhythmias by neuroimmune modulation in myocardial ischemia and reperfusion rat model. $J$. Neuroinflammation 16:139. doi: 10.1186/s12974-019-1513-5

Wang, S., Wu, L., Zhai, Y., Li, X., Li, B., Zhao, D., et al. (2019b). Noninvasive light emitting diode therapy: a novel approach for postinfarction ventricular arrhythmias and neuroimmune modulation. J. Cardiovasc. Electrophysiol. 30, 1138-1147. doi: 10.1111/jce.13974
Wang, S., Zhou, X., Huang, B., Wang, Z., Zhou, L., Wang, M., et al. (2016). Noninvasive low-frequency electromagnetic stimulation of the left stellate ganglion reduces myocardial infarction-induced ventricular arrhythmia. Sci. Rep. 6:30783. doi: 10.1038/srep30783

Wang, Z., Yu, L., Huang, B., Wang, S., Liao, K., Saren, G., et al. (2015). Low-level transcutaneous electrical stimulation of the auricular branch of vagus nerve ameliorates left ventricular remodeling and dysfunction by downregulation of matrix metalloproteinase 9 and transforming growth factor beta1. J. Cardiovasc. Pharmacol. 65, 342-348. doi: 10.1097/FJC.0000000000000201

Wang, Z., Yu, L., Wang, S., Huang, B., Liao, K., Saren, G., et al. (2014). Chronic intermittent low-level transcutaneous electrical stimulation of auricular branch of vagus nerve improves left ventricular remodeling in conscious dogs with healed myocardial infarction. Circ. Heart Fail. 7, 1014-1021. doi: 10.1161/CIRCHEARTFAILURE.114.001564

Wasilczuk, K. M., Bayer, K. C., Somann, J. P., Albors, G. O., Sturgis, J., Lyle, L. T., et al. (2019). Modulating the inflammatory reflex in rats using low-intensity focused ultrasound stimulation of the vagus nerve. Ultrasound Med. Biol. 45, 481-489. doi: 10.1016/j.ultrasmedbio.2018.09.005

Wengrowski, A. M., Wang, X., Tapa, S., Posnack, N. G., Mendelowitz, D., and Kay, M. W. (2015). Optogenetic release of norepinephrine from cardiac sympathetic neurons alters mechanical and electrical function. Cardiovasc. Res. 105, 143-150. doi: 10.1093/cvr/cvu258

Wickramasinghe, S. R., and Patel, V. V. (2013). Local innervation and atrial fibrillation. Circulation 128, 1566-1575. doi: 10.1161/CIRCULATIONAHA.113.001596

Witt, C. M., Bolona, L., Kinney, M. O., Moir, C., Ackerman, M. J., Kapa, S., et al. (2017). Denervation of the extrinsic cardiac sympathetic nervous system as a treatment modality for arrhythmia. Europace 19, 1075-1083. doi: 10.1093/europace/eux011

Yamamoto, K., Lalley, P., and Mifflin, S. (2015). Acute intermittent optogenetic stimulation of nucleus tractus solitarius neurons induces sympathetic longterm facilitation. Am. J. Physiol. Regul. Integr. Comp. Physiol. 308, R266-R275. doi: 10.1152/ajpregu.00381.2014

Yu, L., Dyer, J. W., Scherlag, B. J., Stavrakis, S., Sha, Y., Sheng, X., et al. (2015). The use of low-level electromagnetic fields to suppress atrial fibrillation. Heart Rhythm 12, 809-817. doi: 10.1016/j.hrthm.2014.12.022

Yu, L., Huang, B., Po, S. S., Tan, T., Wang, M., Zhou, L., et al. (2017c). Lowlevel tragus stimulation for the treatment of ischemia and reperfusion injury in patients with ST-segment elevation myocardial infarction: a proof-of-concept study. JACC Cardiovasc. Interv. 10, 1511-1520. doi: 10.1016/j.jcin.2017. 04.036

Yu, L., Huang, B., Wang, Z., Wang, S., Wang, M., Li, X., et al. (2017b). Impacts of renal sympathetic activation on atrial fibrillation: the potential role of the autonomic cross talk between kidney and heart. J. Am. Heart Assoc. 6:e004716. doi: 10.1161/JAHA.116.004716

Yu, L., Huang, B., Zhou, X., Wang, S., Wang, Z., Wang, M., et al. (2017a). Renal sympathetic stimulation and ablation affect ventricular arrhythmia by modulating autonomic activity in a cesium-induced long QT canine model. Heart Rhythm 14, 912-919. doi: 10.1016/j.hrthm.2017.02.010

Yu, L., Scherlag, B. J., Li, S., Fan, Y., Dyer, J., Male, S., et al. (2013). Low-level transcutaneous electrical stimulation of the auricular branch of the vagus nerve: a noninvasive approach to treat the initial phase of atrial fibrillation. Heart Rhythm 10, 428-435. doi: 10.1016/j.hrthm.2012.11.019

Yu, L., Wang, S., Zhou, X., Wang, Z., Huang, B., Liao, K., et al. (2016). Chronic intermittent low-level stimulation of tragus reduces cardiac autonomic remodeling and ventricular arrhythmia inducibility in a post-infarction canine model. JACC Clin. Electrophysiol. 2, 330-339. doi: 10.1016/j.jacep.2015.11.006

Yu, L., Zhou, L., Cao, G., Po, S. S., Huang, B., Zhou, X., et al. (2017d). Optogenetic modulation of cardiac sympathetic nerve activity to prevent ventricular arrhythmias. J. Am. Coll. Cardiol. 70, 2778-2790. doi: 10.1016/j.jacc.2017.09.1107

Zannad, F., De Ferrari, G. M., Tuinenburg, A. E., Wright, D., Brugada, J., Butter, C., et al. (2015). Chronic vagal stimulation for the treatment of low ejection fraction heart failure: results of the NEural Cardiac TherApy foR Heart Failure (NECTAR-HF) randomized controlled trial. Eur. Heart J. 36, 425-433. doi: 10.1093/eurheartj/ehu345

Zhang, Y., Ilsar, I., Sabbah, H. N., Ben David, T., and Mazgalev, T. N. (2009). Relationship between right cervical vagus nerve stimulation 
and atrial fibrillation inducibility: therapeutic intensities do not increase arrhythmogenesis. Heart Rhythm 6, 244-250. doi: 10.1016/j.hrthm.2008.10.043

Zhou, L., Filiberti, A., Humphrey, M. B., Fleming, C. D., Scherlag, B. J., Po, S. S., et al. (2019). Low-level transcutaneous vagus nerve stimulation attenuates cardiac remodelling in a rat model of heart failure with preserved ejection fraction. Exp. Physiol. 104, 28-38. doi: 10.1113/EP087351

Zhou, X., Zhou, L., Wang, S., Yu, L., Wang, Z., Huang, B., et al. (2016). The use of noninvasive vagal nerve stimulation to inhibit sympathetically induced sinus node acceleration: a potential therapeutic approach for inappropriate sinus tachycardia. J. Cardiovasc. Electrophysiol. 27, 217-223. doi: 10.1111/jce.12859

Zipes, D. P. (2008). Heart-brain interactions in cardiac arrhythmias: role of the autonomic nervous system. Clev. Clin. J. Med. 75, S94-S96. doi: 10.3949/ccjm.75.Suppl_2.S94

Zipes, D. P. (2017). Ablation of atrial gangionated plexi to treat symptomatic sinus bradycardia. JACC Clin. Electrophysiol. 3, 960-961. doi: 10.1016/j.jacep.2017.02.010

Zoccal, D. B., Furuya, W. I., Bassi, M., Colombari, D. S., and Colombari, E. (2014). The nucleus of the solitary tract and the coordination of respiratory and sympathetic activities. Front. Physiol. 5:238. doi: 10.3389/fphys.2014. 00238

Zubcevic, J., Richards, E. M., Yang, T., Kim, S., Sumners, C., Pepine, C. J., et al. (2019). Impaired autonomic nervous system-microbiome circuit in hypertension. Circ. Res. 125, 104-116. doi: 10.1161/CIRCRESAHA.119. 313965

Conflict of Interest: The authors declare that the research was conducted in the absence of any commercial or financial relationships that could be construed as a potential conflict of interest.

Copyright $(2020$ Chen, Wang, Li, Yu, Yang, Liu, Tang and Zhou. This is an openaccess article distributed under the terms of the Creative Commons Attribution License (CC BY). The use, distribution or reproduction in other forums is permitted, provided the original author(s) and the copyright owner(s) are credited and that the original publication in this journal is cited, in accordance with accepted academic practice. No use, distribution or reproduction is permitted which does not comply with these terms. 